${ }^{1}$ Clinica Dermatologica, Università degli Studi di Milano, A.O.San Paolo, Via di Rudinì 8,

20142 Milan, Italy

${ }^{2}$ Department of Medicine, Surgery and Dentistry, Division of Pathology, University of Milan, AOS Paolo, Fondazione IRCCS Ospedale Maggiore Policlinico,

Regina Elena e Mangiagalli,

Milan, Italy

${ }^{3}$ Dipartimento di Anestesiologia,

Terapia Intensiva e Scienze

Dermatologiche, Università degli

Studi di Milano-IRCCS Ospedale

Maggiore Policlinico, Mangiagalli

e Regina Elena e Mangiagalli,

Milan, Italy

<berbet@alice.it>

1. Balch $C$, Houghton AN. Diagnosis of metastatic melanoma at distant sites. In: Balch C. Houghton AN, Milton GW, Sober AJ, Soong SJ, eds. Cutaneous melanoma, $2^{\text {nd }}$ ed Philadelphia: JB Lippincott, 1992: 439-67.

2. Abernethy JL, Soyer $\mathrm{P}, \mathrm{Kerl} \mathrm{H}$, et al. Epidermotropic metastatic malignant melanoma simulating melanoma in situ. Am J Surg Pathol 1994; 18: 1140-9.

3. Akasu R, Sugiyama $H$, Araki $M$, et al. Dermatoscopic and videomicroscopic features of melanocytic plantar nevi. Am J Dermatopathol 1996; 18: 10-8.

4. Kornberg $R$, Harris $M$, Ackerman AB. Epidermotropically metastitic malignant melanoma: differntiating malignant melanoma metastatic to the epidermis from malignant melanoma primary in the epidermis. Arch Dermatol 1978; 114: 67-9.

5. Verret J-L, Schnitzler L. Métastases épidermotropes monoméliques d'un mélanome malin: étude évolutive sur 7 ans. Ann Dermatol Venereol (Paris) 1980; 107: 1071-4.

6. Boyd AS, Rapini RP. Acral melanocytic neoplasms: A histologic analysis of 158 lesions. J Am Acad Dermatol 1994; 31: 740-5.

doi: $10.1684 /$ ejd.2010.0849

\section{Giant basal cell carcinoma presenting as a chronic leg ulcer}

A 78-year-old man presented to our department with a 5year history of a non-healing ulcer on his right leg, previously diagnosed as a venous leg ulcer. It started as a small ulcer located on right perimalleolar region and despite several wound care measures, it progressively increased. Medical history was remarkable for benign prostatic hypertrophy and chronic venous insufficiency. No risk factors for atherosclerotic occlusion were present. Physical examination revealed a large circumferential and irregular shaped ulcer, measuring $14 \mathrm{~cm}$ at its largest diameter and occupying the median third of right leg (figure 1A). Its borders were sharply demarcated and raised. The wound bed was hemorrhagic with no visible granulation tissue. Clinical signs of arterial insufficiency were not detected.

Lower limb duplex ultrasonography confirmed bilateral venous insufficiency and arterial stenoses were excluded. A complete laboratory work-up was performed, excluding hematologic, infectious and autoimmune conditions.
A biopsy taken from the ulcer margin showed gland-like structures surrounded by strands of basaloid cells in the dermis and subcutaneous tissue (figure 1B). Those findings were compatible with adenoid basal cell carcinoma (BCC). Several biopsies were taken from the ulcer borders and wound bed and all of them supported the diagnosis of primary BCC (figure 1A). Imaging studies excluded osseous involvement and regional and/or distant metastasis.

The patient refused surgical treatment and radiotherapy was started at a total delivery dose of 60 gray (Gy), divided in 2 Gy fractions, over 6 weeks. This course resulted in a decrease in the depth and extension of the wound. Healing was complicated by local bacterial infections, which were managed with systemic antibiotics, wound debridement and silver dressings. During a 10month follow-up period, a sustained improvement of the leg ulcer was observed (figure 1C). At present, no clinical and/or histological recurrences have been detected.

Chronic ulceration of the lower leg is a frequent condition, with a prevalence of $1-5 \%$ over 65 years of age. The most common causes are venous insufficiency, peripheral arterial disease and diabetes [1]. Malignancies may also present as a leg ulcers, most frequently squamous cell carcinoma (SCC) and $\mathrm{BCC}$, which can be primary or secondary to malignant transformation of chronic ulceration. Chronic wounds may degenerate into SCC and less frequently into BCC. Malignant changes usually manifest as an abnormal vegetating lesion [2]. In our patient, the diagnosis of primary BCC was strongly supported by the positive histopathogical ulcer mapping and by the absence of localized exophytic lesions. Giant BCC is an uncommon skin tumor variant defined as a lesion greater than $5 \mathrm{~cm}$ at its largest diameter. It displays a more aggressive biological behavior, resulting in a higher risk of local invasion and metastasis. Giant BCC is frequently associated with patient neglect, aggressive histological features, previous radiotherapy and long duration. In contrast to ordinary $\mathrm{BCC}$, which is preferentially located in photo-exposed areas, the most frequent localization of
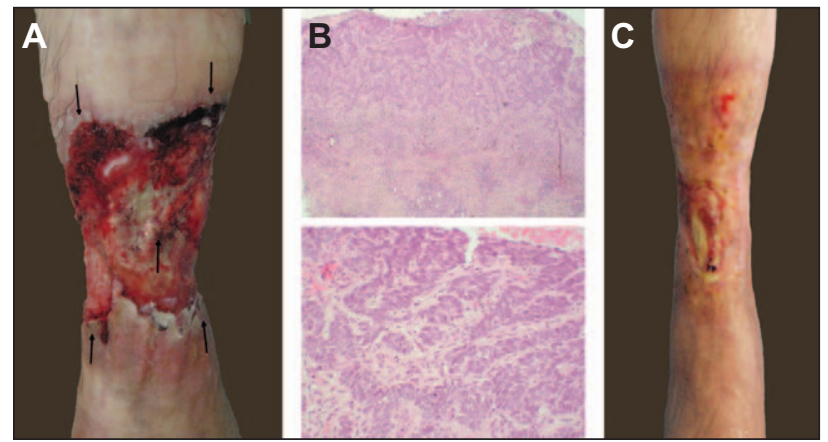

Figure 1. A) Clinical appearance showing a large and circumferential ulcer located on the right leg. Histopathological ulcer mapping with several biopsies (arrows) taken from its borders ( 6 specimens) and wound bed ( 2 specimens) B) Histopathological features of giant basal cell carcinoma. Low power magnification showing basal cell carcinoma with strands and nests of basaloid cells infiltrating the dermis (hematoxylin-eosin stain; original magnification $\times 40$ ). Higher magnification showing a close-up view (hematoxylin-eosin stain; original magnification $\times 200$ ). C) Clinical improvement 10 months after completion of local radiation therapy. 
giant $\mathrm{BCC}$ is the trunk $[3,4]$. Its occurrence in the lower limbs has been rarely reported in the literature [5].

When a slowly enlarging ulcer is the most prominent clinical feature of BCC (rodent ulcer), it can mimic chronic venous leg ulcers, leading to misdiagnosis and consequently to a delay in the beginning of appropriate treatment. Surgery is still the preferred therapy for giant BCC, however, radiotherapy is an alternative with satisfactory outcomes, particularly in older patients with inoperable tumours [6].

We report a giant basal cell carcinoma presenting as a longstanding chronic leg ulcer, emphasising the importance of taking biopsy specimens of all suspicious and non-healing leg ulcers. In our experience, local radiation therapy appears to be an effective non-invasive primary treatment for giant and unresectable basal cell carcinomas of the lower limbs.

Acknowledgements. Conflict of interest: none. Funding sources: none.

Dermatology Department, Hospital
Santo António dos Capuchos,
Alameda Santo António dos
Capuchos, 1169-050 Lisbon,
Portugal
<saralestre@gmail.com>

Sara LESTRE
Vasco SERRÃO
Alexandre JOÃO
Lurdes LOBO
Margarida APETATO

1. Mekkes JR, Loots MA, Van der Wal AC, Bos JD. Causes, investigation and treatment of leg ulceration. $\mathrm{Br}$ J Dermatol 2003; 148: 388-401.

2. Combemale $P$, Bousquet $M$, Kanitakis J, Bernard P. Malignant transformation of leg ulcers: a retrospective study of 85 cases. J Eur Acad Dermatol Venereol 2007; 21: 935-41.

3. Sterry W. Nonmelanoma skin cancer. Eur J Dermatol 2007; 17: 562-3

4. Betti R, Inselvini C, Moneghini L, Crosti C. Giant basal cell carcinomas: report of four cases and considerations. J Dermatol 1997; 24: 317-21.

5. Mainella M, Majewski WT, Latkovich $P$, Michaels BM. Two giant basal cell carcinomas presenting simultaneously in the same patient, one resulting in lower extremity limb loss. Ann Plast Surg 1998; 41: 444-7.

6. Podd TJ. Treatment of lower limb basal cell and squamous cell carcinomas with radiotherapy. Clin Oncol (R Coll Radiol). 1992; 4: 44-5 doi: $10.1684 /$ ejd.2010.0851

\section{Mushroom-like soft fibromas on chronic leg lymphedema}

We present an unusual case of soft fibromas on the legs with lymphedema, seen in a diabetic woman. Only two preceding cases have been reported [1-3]. Comparison of the cases disclosed many common features of this condition.

A 47-year-old woman noticed a hot sensation bilaterally on her legs in July 2004. She had leg edema of two years' duration and a yellowish normal skin colored tumor for 1 year. She had had systemic lupus erythematosus for 22 years and corticosteroid-induced diabetes mellitus for 10 years. She had also lupus nephritis and was treated with prednisolone $(20-30 \mathrm{mg})$ and cyclophosphamide for 9 years. No surgical procedure, which could be related to leg edema, was documented. Physical examination revealed that her weight was $125 \mathrm{~kg}$; height was $160 \mathrm{~cm}$; and her temperature was $38.9{ }^{\circ} \mathrm{C}$. Her legs were markedly swollen with diffuse erythema. There were up to $2-3 \mathrm{~cm}$ sized, partially violaceous, yellowskin colored elastic soft nodules and tumors on both legs with no exudation. Inguinal lymph nodes were not palpable. Complete blood count showed white blood cells,

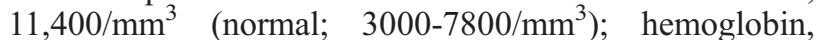
$10.4 \mathrm{~g} / \mathrm{dL}$ (normal; 10.4-14.4 $\mathrm{g} / \mathrm{dL}$ ); total protein, $4.8 \mathrm{~g} / \mathrm{dL}$ (normal; $6.5-8.0 \mathrm{~g} / \mathrm{dL}$ ); and albumin, $3.0 \mathrm{~g} / \mathrm{dL}$ (normal; 4.0-5.2 g/dL). Liver function tests were mostly normal. BUN and creatinine were raised to $51.2 \mathrm{mg} / \mathrm{dL}$ $(7.0-24.0 \mathrm{mg} / \mathrm{dL})$ and $3.65 \mathrm{mg} / \mathrm{dL}(0.4-0.9 \mathrm{mg} / \mathrm{dL})$, respectively. C-reactive protein showed $29.94 \mathrm{mg} / \mathrm{dL}$ $(<0.5 \mathrm{mg} / \mathrm{dL})$. She was admitted to our hospital under the diagnosis of cellulitis with lymphedema, and antibiotics with $\gamma$-globulin therapy were initiated to control severe infection, with a good response.

She had similar episodes of cellulitis in April, May and July 2005 (figure 1A). During the course, yellowish normal skin-colored mushroom-like tumors increased in number and enlarged on her legs. The tumors were more prominent on her right leg and were not seen on the thighs.
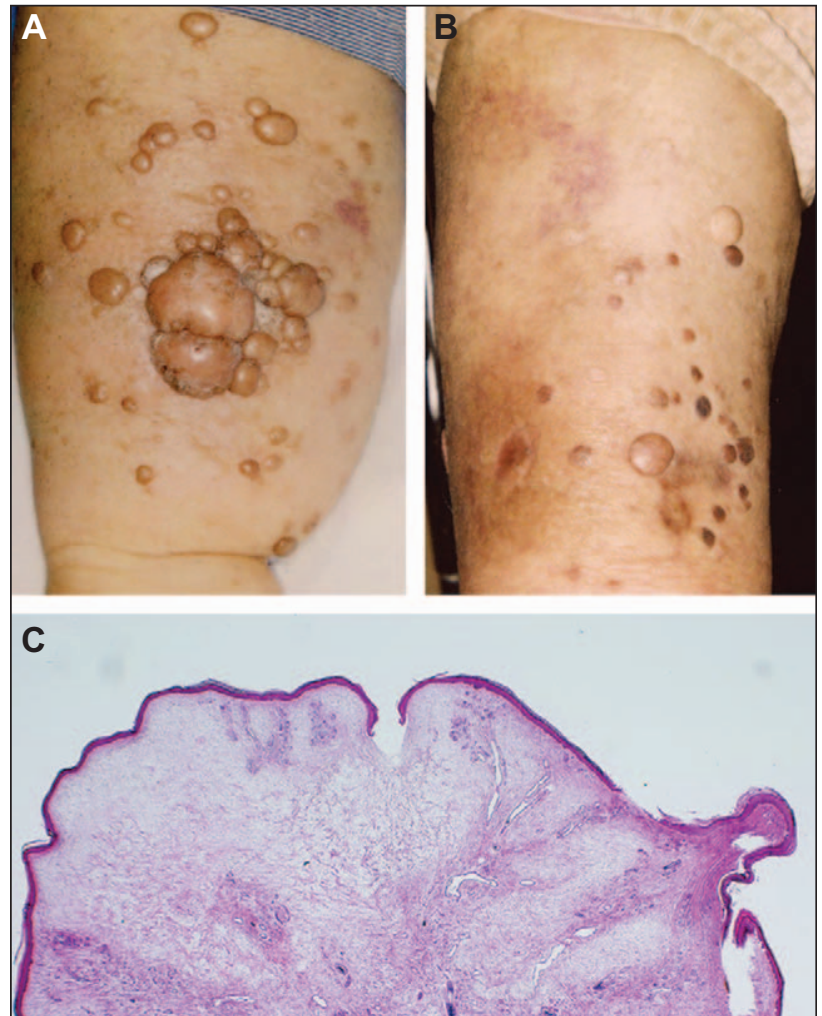

Figure 1. Clinical presentation of the skin tumors. The lesions were up to $2-3 \mathrm{~cm}$ sized, partially violaceous, yellow-skin colored, elastic soft tumors and nodules. These tumors are enlarged and increased in number, and presented as mushroom-like (Jul. 2005). B) Almost all fibromas are subsiding. Most but not all the tumors are gone. (Sep. 2007). C) Histopathological findings (Hematoxylin-Eosin stain). Low magnification $(\times 40)$. Dome-shaped pedunculated tumor. Inflammatory infiltrate is observed. Hyper-vascularity and dilated vessels are noted. 